\title{
Review of Available Data for Validation of Nuresim Two-Phase CFD Software Applied to CHF Investigations
}

\author{
D. Bestion, ${ }^{1}$ H. Anglart, ${ }^{2}$ D. Caraghiaur, ${ }^{2}$ P. Péturaud, ${ }^{3}$ B. Smith, ${ }^{4}$ M. Andreani, ${ }^{4}$ \\ B. Niceno, ${ }^{4}$ E. Krepper, ${ }^{5}$ D. Lucas, ${ }^{5}$ F. Moretti, ${ }^{6}$ M. C. Galassi, ${ }^{6}$ J. Macek, ${ }^{7}$ L. Vyskocil, ${ }^{7}$ \\ B. Koncar, ${ }^{8}$ and G. Hazi ${ }^{9}$ \\ ${ }^{1}$ Commissariat à l'Énergie Atomique (CEA), DEN-DER-SSTH, 17 Rue des Martyrs, 38054 Grenoble, France \\ ${ }^{2}$ Reactor Technology Division, Physics Department, Royal Institute of Technology (KTH), AlbaNova University center, \\ 10691 Stockholm, Sweden \\ ${ }^{3}$ Électricité de France (EDF) R\&D, Mécanique des Fluides Energie et Environnement, 6 quai Watier, 78401 Chatou, France \\ ${ }^{4}$ Department of Nuclear Energy and Safety, Thermal-Hydraulics Laboratory, Paul Scherrer Institute (PSI), \\ CH-5232 Villigen, Switzerland \\ ${ }^{5}$ Forschungszentrum Dresden-Rossendorf (FZD) P.O.Box 510119, D-01314 Dresden, Germany \\ ${ }^{6}$ Department of Mechanics, Nuclear and Production Engineering - DIMNP, Università di Pisa, 2, Via Diotisalvi, 56100 PISA, Italy \\ ${ }^{7}$ Department of Thermal-Hydraulic Analyses, Nuclear Research Institute Rez plc (NRI), 25068 Rez, Czech Republic \\ ${ }^{8}$ Josef Stefan Institute (JSI), Jamova 39, 1000 Ljubljana, Slovenia \\ ${ }^{9}$ KFKI Atomic Energy Research Institute, Theoretical Thermohydraulics, Research Group, 1525 Budapest, Hungary
}

Correspondence should be addressed to D. Bestion, dominique.bestion@cea.fr

Received 24 January 2008; Accepted 23 May 2008

Recommended by Iztok Tiselj

The NURESIM Project of the 6th European Framework Program initiated the development of a new-generation common European Standard Software Platform for nuclear reactor simulation. The thermal-hydraulic subproject aims at improving the understanding and the predictive capabilities of the simulation tools for key two-phase flow thermal-hydraulic processes such as the critical heat flux (CHF). As part of a multi-scale analysis of reactor thermal-hydraulics, a two-phase CFD tool is developed to allow zooming on local processes. Current industrial methods for CHF mainly use the sub-channel analysis and empirical CHF correlations based on large scale experiments having the real geometry of a reactor assembly. Two-phase CFD is used here for understanding some boiling flow processes, for helping new fuel assembly design, and for developing better CHF predictions in both PWR and BWR. This paper presents a review of experimental data which can be used for validation of the two-phase CFD application to CHF investigations. The phenomenology of DNB and Dry-Out are detailed identifying all basic flow processes which require a specific modeling in CFD tool. The resulting modeling program of work is given and the current state-of-the-art of the modeling within the NURESIM project is presented.

Copyright (C) 2009 D. Bestion et al. This is an open access article distributed under the Creative Commons Attribution License, which permits unrestricted use, distribution, and reproduction in any medium, provided the original work is properly cited.

\section{Introduction}

The NURESIM Integrated Project of the 6th European Framework Programme is envisaged to provide the initial step towards a common European Standard Software Platform for modeling, recording, exchanging, and recovering data for nuclear reactors simulations. Key objectives of NURESIM include the integration of advanced physical models in a shared, open software platform, incorporating the latest advances in reactor core physics, thermal hydraulics, and coupled multiphysics modeling. The specific objectives of NURESIM are to initiate the development of the next generation of experimentally validated, "best-estimate" tools with improved prediction capabilities, standardization, and robustness to address current and future needs of industry, reactor safety organizations, academic, government, and private institutions.

The overall objective of NURESIM thermal-hydraulic subproject is to improve the understanding and the predictive capabilities of the simulation tools for key two-phase 
flow thermal-hydraulic processes that can occur in nuclear reactors, focusing on two high priority issues, the critical heat flux (CHF), and the pressurized thermal shock (PTS). This overall objective has resulted from the conclusions of the EUROFASTNET [1] concerted action, which established a priority list of 44 industrial needs, and the results of the ASTAR [2], and ECORA [3] projects of the 5th Framework Programme are considered as inputs for NURESIM. The initial framework for performing the tasks is provided by the Neptune [4-6] two-phase CFD module, which is being developed by CEA and EDF, under the cosponsorship of AREVA-NP and IRSN. Other CFD tools such as CFX or FLUENT are also used within the NURESIM project. This paper focuses on the CHF investigations and primarily on the use of the two-phase CFD for both departure from nucleate boiling (DNB) and dryout investigations.

This paper presents a review of existing experimental data bases which can be used for validation of the two-phase CFD application to critical heat flux (CHF) investigations with respect to nuclear reactors. The phenomenology of DNB and dryout is detailed identifying all basic flow processes which require a specific modeling in CFD tool. The resulting programme of work is given, and the current state of the art of the modeling is presented.

\section{The Multiscale Analysis of CHF}

Four basic spatial scales encountered in thermal-hydraulic phenomena relevant to nuclear power plants:

(i) system scales, which are addressed by zero- and onedimensional flow models for pipes, pumps, valves, breaks, and control systems together with CFD methods for porous media;

(ii) component-scales, which are addressed by CFD methods for porous media (typically for the core of a reactor or for the steam generators with a minimum spatial resolution in the case of the subchannel analysis);

(iii) mesoscales, which are addressed by computational fluid dynamics (CFDs) methods in open medium, including turbulence models, using either Reynoldsaveraged simulations (RANSs) or large eddy simulation (LES);

(iv) microscales, which are addressed by direct numerical simulation (DNS) and interface tracking methods (ITMs) that focus on a very small domain (e.g., a domain containing a few bubbles or droplets).

In $\mathrm{CHF}$ investigations, the present industrial methods mainly use the component scale with 3D modeling of core assemblies using in the hot assembly the subchannel analysis. Large-scale experiments having the real geometry of the reactor assembly are used to develop empirical correlation for the CHF as function of flow variables which are averaged over the cross-section of a subchannel. The NURESIM-TH activities regarding CHF aim at using two-phase CFD as a tool for understanding boiling flow processes, in order to subsequently help new fuel assembly design and to develop better CHF predictions in both PWR and BWR. A "local predictive approach" may be envisaged for the long term where CHF correlations would be based on local (mesoscale) $\mathrm{T} / \mathrm{H}$ parameters provided by CFD. If the processes leading to $\mathrm{DNB}$ and dryout are well understood, the CHF correlation will be physically based, but one may also develop empirical correlations if some phenomena are not clearly identified.

Considering the rather low maturity of two-phase CFD, a general methodology was proposed by a Writing Group of the OECD-CSNI (see Bestion et al. 2006 [7]) to apply it to a reactor issue with successive steps:

(i) identification of all important flow processes of the application,

(ii) selecting a basic model,

(iii) filtering turbulent scales and two-phase intermittency scales,

(iv) identification of local interface structure,

(v) modeling interfacial transfers,

(vi) modeling turbulent transfers,

(vii) modeling wall transfers,

(viii) use of finer scale simulations for modeling,

(ix) identification of validation and verification test cases with possibly some demonstration test cases.

The choice of a validation test matrix and of the basic modeling approach should be consistent with each other since there must be enough measured physical parameters to be able to validate separately each sensitive process modeled in the equations.

The identification of the basic flow processes related to both DNB and dryout and a review of available experimental data were performed before selecting a basic model and defining a development and validation programme. Next sections will present this initial work and will conclude on the present state of the art in the modeling within the NURESIM project.

\section{Departure from Nucleate Boiling}

3.1. The DNB Phenomenology. Departure from nucleate boiling is the main governing critical heat flux mechanism for pressurized water reactors. A huge amount of work has been devoted to the DNB in the past decades but the evaluation of the CHF still relies on fully empirical methods.

Rod bundles with spacer grids are tested in real conditions with the fuel assembly geometry and the same flow $\mathrm{T} / \mathrm{H}$ conditions as in the reactor. Such experiments are very expensive and time consuming but necessary to determine the CHF behaviour of any new fuel assembly design.

The reason of this situation is that the phenomenology of convective boiling and DNB is very complex, and many small-scale processes are not well understood. It is very likely that phenomena occurring at various scales play a role; one can distinguish three scales for reactor DNB phenomenology. 
(i) The macroscale refers to phenomena at the scale of the subchannel (e.g., about $1 \mathrm{~cm}$ ). Macroscale phenomena are modeled in subchannel analysis codes.

(ii) The mesoscale refers to flow processes responsible for the profiles of the main flow parameters within subchannels (e.g., about 0.1 or $1 \mathrm{~mm}$ ). Mesoscale flow processes can be modeled in two-phase CFD simulation tools.

(iii) Microscale phenomena occur at the scale of the smallest bubbles or nuclei and can only be numerically simulated by direct numerical simulation (DNS) tools and interface tracking methods (ITMs).

A nonexhaustive list of flow processes at the various scales is given here below.

\section{MICROSCALE Phenomena}

(i) Activation of nucleation sites.

(ii) Evolution of active sites density with increasing power.

(iii) Growing of attached bubbles.

(iv) Sliding of attached bubbles along heating wall.

(v) Coalescence of attached bubbles.

(vi) Extension of dry patch.

(vii) Effects of wall conductivity and heat capacity.

(viii) Detachment of bubbles.

(ix) Rewetting after detachment.

(x) Mutual influence of neighboring nucleation sites.

(xi) Influence of flow characteristics on local processes: external convective velocity.

(xii) Behaviour of detached bubbles: coalescence, migration.

(xiii) Interactions between detached bubbles.

(xiv) Forces between detached bubbles and liquid flow.

(xv) Formation of high-void layer if bubbles cannot escape due to counter current flow limitation (CCFL) type phenomenon and behaviour of the thin liquid film which vaporizes below the bubble layer.

\section{MESOSCALE Phenomena}

(i) Wall to fluid heat transfer in subcooled boiling: liquid heating, vaporization, quenching.

(ii) Transport and dispersion of bubbles.

(iii) Vaporization-condensation of bubbles.

(iv) Coalescence and breakup of bubbles.

(v) Turbulent transfers of heat and momentum within liquid.

(vi) Effects of polydispersion of bubbles on interfacial transfers

(vii) Local effects of grids: enhanced turbulence and flow rotation.

\section{MACROSCALE Phenomena}

(i) Mixing between subchannels, cross-flows, turbulence.

(ii) Grid spacers effects on mixing between sub-channels.

(iii) Effects of cross-sectional averaged pressure $P$, mass flux, $G$, and quality $X$ th, on DNB occurrence.

(iv) Effects of nonuniform heat flux on DNB occurrence.

(v) Effects of spacer grids on DNB occurrence.

Two-phase CFD predictions should be compared to relevant experimental data in order to validate all mesoscale flow processes, in geometrical and $\mathrm{T} / \mathrm{H}$ conditions preferably representative of the industrial ones. This will bring a better understanding of the effects of the mesoscale phenomena on the CHF occurrence. Moreover, microscale flow phenomena should also be better understood for developing physically based closure laws in the CFD approach. In this purpose, any experimental information on such microscale phenomena or any DNS simulations may be used to improve the CFD simulation tool. However, this project did not bring enough information to build a physically based DNB criterion. Nevertheless, CFD simulations of boiling flowup to DNB have the potentiality to predict some mesoscale effects on flow conditions at the wall such as the development of twophase boundary layers, or spacer grid effects, which are not seen by the subchannel analysis and current empirical $\mathrm{CHF}$ models. One may at least expect that the effects of nonuniform axial heat flux, which are now empirically modeled, may be simply seen by local conditions resulting from CFD predictions. Also the effects of spacer grid design on flow conditions seen by the wall may be described at the CFD scale whereas subchannel analysis can only describe the associated pressure loss, the additional mixing between neighboring subchannels and the effect on CHF when experimental data are available.

3.2. Review of the Data Basis for DNB. The following data sources were reviewed and analysed with respect to their interest for validating CFD tools used in DNB investigations. Table 2 summarizes the characteristics of the experiments, the measured parameters, and the correspondence between mesoscale phenomena and the available data. Some of these experiments provide data which may be far from flow conditions encountered in reactors when CHF occurs. However, they allow a separate effect validation with increasing complexity of the phenomenology. The "local predictive approach" requires that all local (mesoscale) T/H parameters be correctly predicted by CFD since the CHF criterion will be expressed as a function of them.

There are single phase liquid data (AGATE) which may be used as a first step in the validation of turbulence models in a rod bundle with spacer grids. Some air-water bubbly flow data (DEDALE, TOPFLOW) may be used as a first step in the validation of models for bubble transport and dispersion, coalescence and breakup, effects of polydispersion on interfacial forces, and momentum turbulent transfers. Boiling flow data in simple geometry (DEBORA, ASU, 
Purdue data, KAERI data) either in steam-water of Freon (R12, R113) may then be used to further validate in more representative conditions (pressure is either atmospheric or similar to reactor conditions) the models already investigated in air-water conditions, with additional effects of wall heat transfers, turbulent heat transfers and interfacial heat, and mass transfers due to vaporization and condensation. Some DEBORA data were recorded in conditions which were very close to $\mathrm{CHF}$ occurrence. Effects of spacers are also validated in boiling flow conditions with the DEBORA-Promoter data. BFBT data are used to validate the void distribution of a steam-water boiling flow in a real BWR rod bundle geometry. These data are unique and can also be used to some extent for DNB investigations if one considers the low quality data. LWL data in a real-rod bundle of a WWER reactor finally allow a global validation of the boiling flowup to DNB.

3.2.1. DEDALE Air-Water Bubbly Flow Tests. DEDALE is an adiabatic air-water two-phase experimental programme performed at EDF/DER [8]. DEDALE aimed at analyzing the axial development of a bubbly flow in a vertical pipe up to the transition to slug flow and creating an accurate and reliable data base with local information for the validation of dynamics-related models in CFD tools $[9,10]$.

3.2.2. DEBORA Boiling Flow Tests in a Heated Pipe. The DEBORA experiment [11] was carried out at the Commissariat à l'Energie Atomique, Grenoble, France, to provide a reliable local data base on boiling phenomena (up to DNB) in PWR T/H condition ranges, in order to eventually achieve a better understanding and prediction of DNB-type boiling. Calculations and analysis with Neptune are reported in [12].

The test section is an electrically heated vertical tube with upward R12 boiling flow simulating PWR in-core $\mathrm{T} / \mathrm{H}$ conditions, with local measurements along a diameter within the outlet tube cross section of both steam phase characteristics (void fraction, interfacial area concentration, bubble size, and mean axial velocity) and liquid phase parameter (temperature).

3.2.3. DEBORA Tests in a Heated Pipe with a Turbulence Promoter/Enhancer (Swirl Flows). The "DEBORAPromoter" tests (see Figure 1) with a vane type turbulence promoter/enhancer were carried out in addition to the previous ones, to characterize the two-phase boiling flow behaviour in a complex geometry representing the industrial one. The test section is similar to the previous one, with addition of a turbulence promoter/enhancer located inside the tube either $23.5 \mathrm{D}$ or $10 \mathrm{D}$ upstream from the end of the heated length.

Validation of CFD tools on these tests provides additional information on the effect of spacer grid wake on the mixing of bubbles generated at the wall and on the effects of the flow rotation on the void repartition; simulations of such tests with Neptune_CFD were presented [13].

3.2.4. AGATE Single-Phase Tests. The AGATE experiment has been developed in CEA Grenoble. Two-test sections were used: (i) "AGATE-Grid" consists of a $5 \times 5$ rod bundle inside a squared-section housing with a mixing vane grid;

(ii) "AGATE-Promoter" with a similar geometry as "DEBORA-Promoter" one (i.e., pipe with a 3-vane turbulence enhancer).

Nonheated water flows upwardly in the vertical test section, and velocity measurements are made using laser Doppler anemometry (LDA). Both the mean velocity and velocity fluctuations are measured in order to investigate the effects of the grid or promoter.

The data allow to validate the turbulence modeling with spacer grid (or turbulence promoter/enhancer) effects in single-phase conditions. They were used for validation of a 1D model with $k \& \varepsilon$ model [14].

3.2.5. QLOVICE Visualisation Tests. QLOVICE tests are being performed by CEA in order to investigate basic processes associated with DNB. QLOVICE is a visualization of pool boiling with high-speed video-camera.

(i) A transparent heated bottom wall allows to visualise the bubble nucleation and detachment.

(ii) A side window allows to see bubble behaviour after detachment.

First tests were performed and have clearly shown the dry patch evolutions. It was observed

(i) bubble sliding along the heating wall before detachment,

(ii) sudden large size dry patch extension observed followed by a wall rewetting,

(iii) many bubble clusters,

(iv) interactions between neighbouring nucleation sites.

Two main processes are assumed to play a significant (dominant) role on the DNB occurrence: a sudden extension of dry patch up to DNB or a CCFL type phenomenon with bubbles which cannot escape from wall after detachment. However, no conclusion can be presently drawn on the dominant process.

3.2.6. Arizona State University (ASU) Tests of Boiling Flow in a Heated Annular Channel. Experiments of turbulent subcooled flow in a vertical annular channel were carried out at the Arizona State University [15-18] to provide detailed information on average flow structure, temperature, and gas and liquid flow fields in fully developed nucleate boiling, as well as on turbulent variables controlling transport mechanisms. In the experiment, R-113 was the working fluid.

Validation of CFD tools on ASU tests provides information on the steam production at the wall in subcooled boiling, on the interfacial forces responsible for the void profiles, on interfacial heat and mass transfers, on interfacial area concentration evolution, and on turbulence in the bubbly boundary layer. 

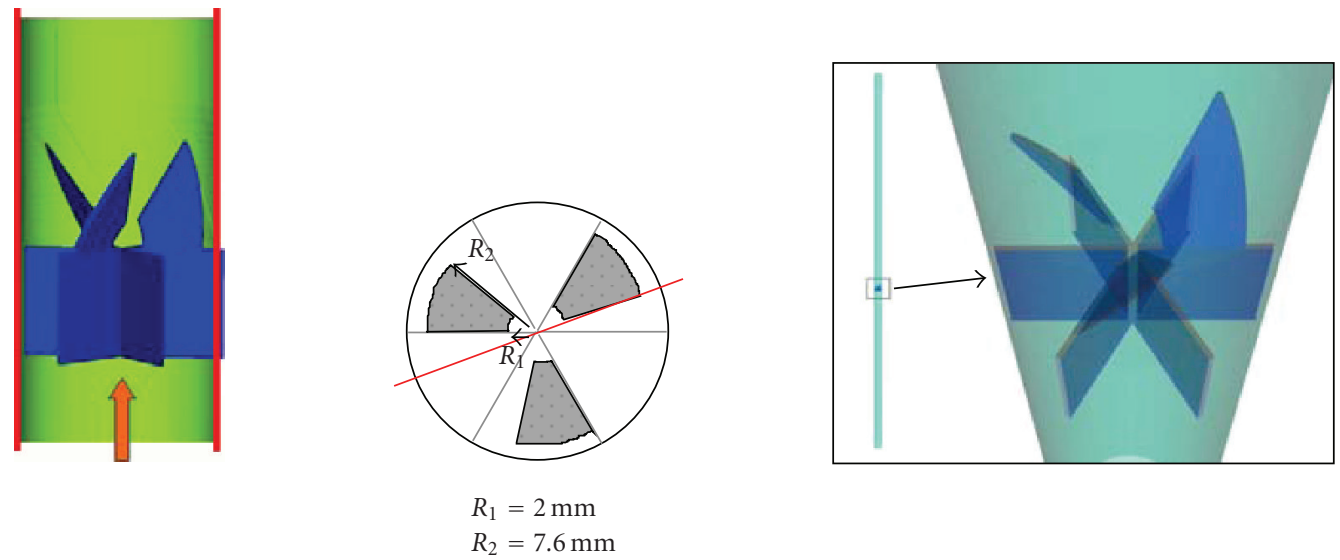

Figure 1: "DEBORA-promoter" geometry.

Measurements used simultaneously a two-component laser Doppler velocimetry for liquid velocity and a fast response cold-wire for temperature field, as well as a dualsensor fiber optic probe for the vapour fraction and vapour axial velocity.

A comparison of Neptune simulations with the early tests was presented in [17].

\subsubsection{Purdue University (PU/NE) Tests of Boiling Flow in a} Heated annular Channel. Experiments have been carried out at the School of Nuclear Engineering of Purdue University in an internally heated annulus to provide local measurements of void fraction, interfacial area concentration, and interfacial velocity in subcooled boiling [19-22]. Water at atmospheric pressure was the working fluid. Influence of inlet liquid temperature, heat flux, and inlet liquid velocity on local flow parameters was specially investigated. The chosen geometry and set of conditions were aimed at scaling the conditions of a BWR. Although properties at 70 bar could not be represented, geometrical, hydrodynamic, and thermal similarities for the flow boiling processes were preserved.

Earlier tests $[19,20]$ include information on the axial evolution of the measured variables, and preliminary studies [19] addressed the dependence of bubble size before detachment on the axial position.

Visual observations of the boiling processes provided essential information on the displacement between the location of net vapor generation (NVG) and the location of bubble detachment [19]. More recent photographic studies of bubble lift-off diameters have been presented by Situ et al. [22-24].

A few analyses to test the validity of CFD codes have been carried out using the earlier series of test data $[25,26]$.

3.2.8. KAERI Tests of Boiling Flow in a Heated Annular Channel. Experiments have been carried out at the Korea Atomic Energy Research Institute (KAERI) in an internally heated annulus to provide local measurements of void fraction and phase velocities in subcooled boiling [27-
29]. Water at low pressure ( 1 to 2 bar) is the working fluid. The aim was to provide a database for subcooled boiling modeling, including aspects such as force balances for departing vapour bubbles and bubble population balance.

Measurements of void fraction and bubble velocity were taken using a double-sensor conductivity probe. Liquid velocities were measured by a Pitot tube, correcting for the effect of bubbles [30]. Data included radial distributions of void fraction, axial liquid, and vapour velocity, interfacial area concentration (three tests only, [28]), Sauter mean diameter (three tests in [28], two more in [30]), bubble concentration (bubbles/unit volume, three tests only, [28]).

Tests have been used for assessing the CFX-4 code [2731] especially the performance of an extension to 15 bubble classes of the MUSIG model.

3.2.9. Experimental Data on TOPFLOW Loop on Two Phase Flow in a Vertical Tube. The structure of an adiabatic airwater and of steam-water flow with reduced condensation and with slight subcooling in a vertical pipe of $195.3 \mathrm{~mm}$ inner diameter (DN200) was studied using wire-mesh sensors. The experiments were performed at the two-phase FLOW test facility (TOPFLOW) [32] of Safety Research of Forschungszentrum Dresden-Rossendorf e.V., which can be operated for pressure up to $7 \mathrm{MPa}$ and temperature up to $286^{\circ} \mathrm{C}$. Air-water data at ambient conditions and steamwater data under nearly adiabatic conditions as well as with slightly subcooled water are available for pressures of 1 and $2 \mathrm{MPa}$. Wire-mesh sensors can characterize the shape of large bubbles, since they acquire the phase distribution in the entire cross-section. By changing the injecting position of the gas supply during the next test, it is possible to study the evolution of the flow structure along the flow path in the DN200 vertical pipe.

Function and construction of wire-mesh sensors are described in [33]. Cross-section averaged gas fractions as well as radial gas fraction profiles can be calculated [34]. Radial gas velocity profiles were obtained by means of a point-topoint cross-correlation between the signals of both sensors placed in a distance of $63 \mathrm{~mm}$ behind each other [35]. Bubble 
size distributions were extracted from the measuring data using the algorithm described by [36].

A technique to analyse the evolution of the flow structure is the calculation of radial gas fraction profiles decomposed according to bubble size classes [34]. The method was used to decompose the radial gas fraction profiles into 4 bubble size classes: class 1 from 0 to $4.8 \mathrm{~mm}$ equivalent diameter, class 2 from 4.8 to $5.8 \mathrm{~mm}$, class 3 from 5.8 to $7.0 \mathrm{~mm}$, and class 4 above $7.0 \mathrm{~mm}$. Here, $5.8 \mathrm{~mm}$ is the critical diameter for the inversion of the lift-force according to Tomiyama [37] for air bubbles in water at ambient temperature. It decreases in case of steam-water flow with increasing pressure.

A visualisation (see Figure 2) is done by generating virtual side projections and side views of virtual central cuts from the mesh-sensor data according to the algorithms described in [38]. For each mesh-sensor data set, virtual side views and virtual centre cuts are combined in the same image. The height-to-width relation of the depicted bubbles is nearly respected in this image. It is visible how bubbles injected at the periphery move towards the centre of the pipe in case of the reference experiment without subcooling, while in the experiment with condensation the bubble density decreases with growing distance from the injection device.

The data can be used to test the complex interaction of local bubble distributions, bubble size distributions, and local heat and mass transfer. The lateral motion of the bubbles in a shear flow, bubble coalescence, and breakup and the phase transfer can be observed by measurements along the pipe. For example, the radial distribution of bubbles strongly depends on their diameter. For a vertical cocurrent upwards flow, smaller bubbles tend to move towards the wall, while large bubbles are preferably found in the centre. Details on the steam-water experiments and investigations on the modeling of such flows are presented by Lucas and Prasser [39].

\subsubsection{BFBT Data on Void Fraction Distribution in BWR} Fuel Assembly. Experimental tests for measuring the void fraction distribution inside boiling water reactor (BWR) fuel assemblies have been conducted by the Nuclear Power Engineering Corporation (NUPEC), Tokyo, Japan, by the use of an experimental facility referred to as BFBT (BWR Fullsize Fine-mesh Bundle Tests). Data provided by such facility have been initially used for subchannel code assessment [40] and are currently being used for CFD code assessment in the framework of an OECD-NEA/US-NRC Benchmark. Xray $\mathrm{CT}$ scanner and $\mathrm{X}$-ray densitometers are employed to measure the void fraction distribution in a BWR full-scale fuel assembly under steady-state and transient conditions.

The test loop has a full range of steady-state void fraction testing capabilities over BWR operating conditions. Unsteady characteristics, flow changes, power changes, and complicated BWR operational transients are simulated too.

The test section consists of a full-scale BWR fuel assembly simulator, which is made of electrically heated rods able to reproduce the actual power profiles generated by nuclear fission. The instrumentation allows measurements of temperature, flow rate, pressure and, mainly, void fraction.
An X-ray CT scanner, consisting of an X-ray tube and 512 detectors, is employed to measure the void fraction in the upper part of the test section in steady-state conditions. The void fraction data have a $0.3 \times 0.3 \mathrm{~mm}^{2}$ resolution. Such a high resolution makes those data useful for CFD code validation.

\subsubsection{Large Water Loop Experimental Test Facility. The large} water loop has been built at the NUCLEAR MACHINERY PLANT, ŠKODA, Plzen Ltd., Plzen, Czech Republic. The loop is a nonactive pressurized-water equipment with technological and thermal parameters corresponding to those of PWR. The possible parameter ranges are suitable for all types of pressurized water reactors. The CHF experimental facility (a part of large water loop) has been designed for the research of CHF in water flow through a bundle of electrically heated rods.

The test sections were formed by 7 or 19 parallel electrically heated rods with external diameters of $9 \mathrm{~mm}$. Axial and radial uniform or nonuniform heat flux distribution and water up flow were used in the tests. The rods were with direct heating were specially manufactured with axially varying wall thickness while maintaining a constant outside diameter to achieve nonuniform axial heat flux. The rods ( $3500 \mathrm{~mm}$ long) were placed in regular hexagonal geometry with a pitch of $12.5-13 \mathrm{~mm}$. Critical conditions were obtained under constant thermal-hydraulic conditions by gradually increasing heat input.

\subsection{Development and Validation Programme of Work. Based} on data and manpower availability, the following programme of validation was planed to be performed within the NURESIM project (see Table 1). Validation $(V)$ tests allow to draw conclusions on the validity of some models whereas demonstration $(D)$ tests check the capability of a software to simulate a complex process.

Table 2 presents the correspondence between the above data sources and the basic phenomena at the mesoscale.

The present data basis is not sufficient to validate all phenomena of interest, and the main defaults are the lack of turbulence data in high void bubbly flow and the lack of data for validation of the heat flux partitioning at the wall in convective nucleate boiling. More generally no data can provide information on microscale phenomena which makes the development of physically based models in the near wall region difficult.

\subsection{State of the Art in DNB Modeling Within the NURESIM} Project. The following state of the art on the modeling of two-phase flow up to DNB occurrence results from the ongoing work in NURESIM which mainly addressed flow conditions before DNB.

(1) Basic model: as boiling bubbly flows are encountered, the two-fluid model is naturally used in this flow conditions to benefit from the possibility to model all interfacial forces acting on the bubbles such as drag, lift, turbulent dispersion, virtual mass, and wall forces which control the void repartition in a boiling channel. The choice of the 


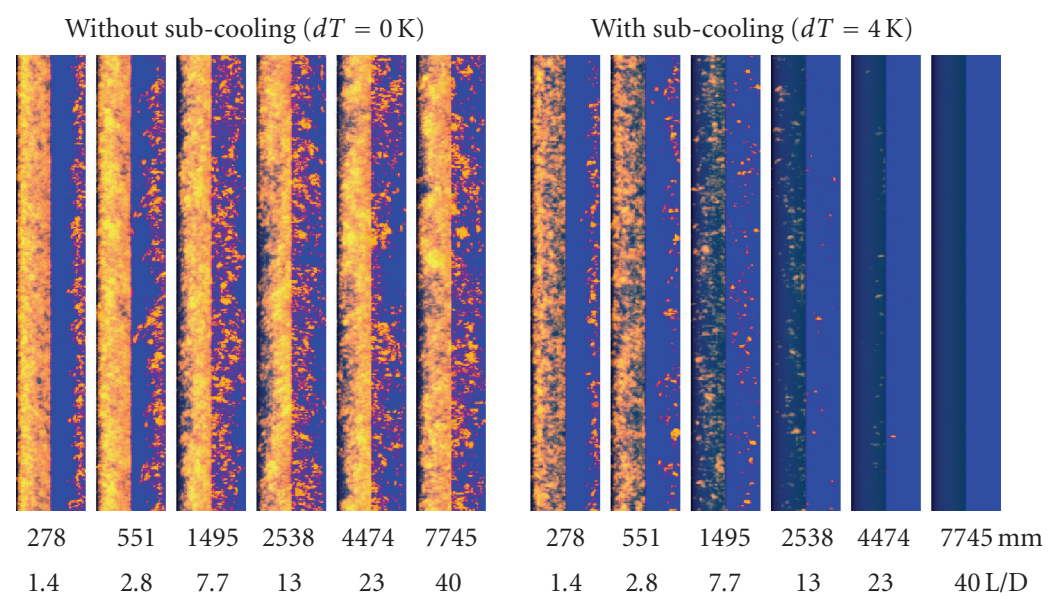

Distance between steam injection and sensor (inlet length)

Figure 2: Virtual side projections (left halves of the columns) and side views of virtual central cuts (right halves) of the mesh-sensor data (from [39]).

TABLE 1: Planed validation and demonstration calculations within NURESIM project.

\begin{tabular}{|c|c|c|}
\hline Validation tests and demonstration tests & $\begin{array}{l}\text { Validation } \\
\text { Demonstration }\end{array}$ & Main interest of validation \\
\hline DEBORA & $\mathrm{V}$ & Investigations of wall heat transfer models \\
\hline DEBORA tests close to CHF conditions & $\mathrm{V}$ & $\begin{array}{l}\text { Looking for processes responsible for void accumulation } \\
\text { close to the wall }\end{array}$ \\
\hline $\begin{array}{l}\text { DEBORA and/or TOPFLOW polydispersed } \\
\text { data }\end{array}$ & $\mathrm{V}$ & Validation of the method of statistical moments \\
\hline TOPFLOW polydispersed data & $\mathrm{V}$ & Validation of the MUSIG method \\
\hline DEBORA polydispersed data & $\mathrm{V}$ & Validation of the MUSIG method \\
\hline DEDALE & $\mathrm{V}$ & Evaluation of LES simulation of bubbly flow \\
\hline ASU boiling water experiment & $\mathrm{V}$ & $\begin{array}{l}\text { Validation of wall function } \\
\text { Evaluation of LES simulation of boiling bubbly flow }\end{array}$ \\
\hline BFBT experiments & VD & $\begin{array}{l}\text { Evaluation of models controlling void distribution in ac- } \\
\text { tual core geometry }\end{array}$ \\
\hline DEBORA & $\mathrm{V}$ & Investigations of wall heat transfer models \\
\hline Large water loop (LWL) & VD & Evaluation of CHF prediction CFD in actual core geometry \\
\hline
\end{tabular}

method to model poly-dispersion effects remains partly open.

(2) Averaging or filtering equations: considering flow in a PWR core in conditions close to nominal, when boiling occurs, a high velocity steady flow regime takes place with times scales associated to the passage of bubbles being very small $\left(10^{-4}, 10^{-3} \mathrm{~s}\right)$ and with bubble diameter being rather small $\left(10^{-5}\right.$ to $\left.10^{-3} \mathrm{~m}\right)$ compared to the hydraulic diameter (about $10^{-2} \mathrm{~m}$ ). These are perfect conditions to use a time average or ensemble average of equations as usually done in the RANS approach. All turbulent fluctuations and twophase intermittency scales can be filtered since they are significantly smaller than scales of the mean flow. The use of a large eddy simulation (LES) approach may allow to simulate bubble dispersion by liquid turbulence instead of modeling it. This LES approach has been used with success in bubble plume simulations but cannot replace the RANS approach for convective boiling flows.

(3) Identification of local interface structure: there is a unique interfacial structure corresponding to a dispersed gas phase in a continuous liquid. As long as bubbly flow is encountered, there is no need to develop an identification of the local flow regime and there is no need to use an ITM. Going to DNB occurrence, a gas layer appears and a criterion must be implemented for identifying this occurrence. A very simple criterion based on the local void fraction was applied to LWL tests. However, the description of the interface structure may require addition of transport equations such as interfacial area transport (IAT) or bubble number density transport. More generally, the method of the statistical moments (MMSs) can be used to characterise the poly-dispersion of the vapour phase with a bubble 


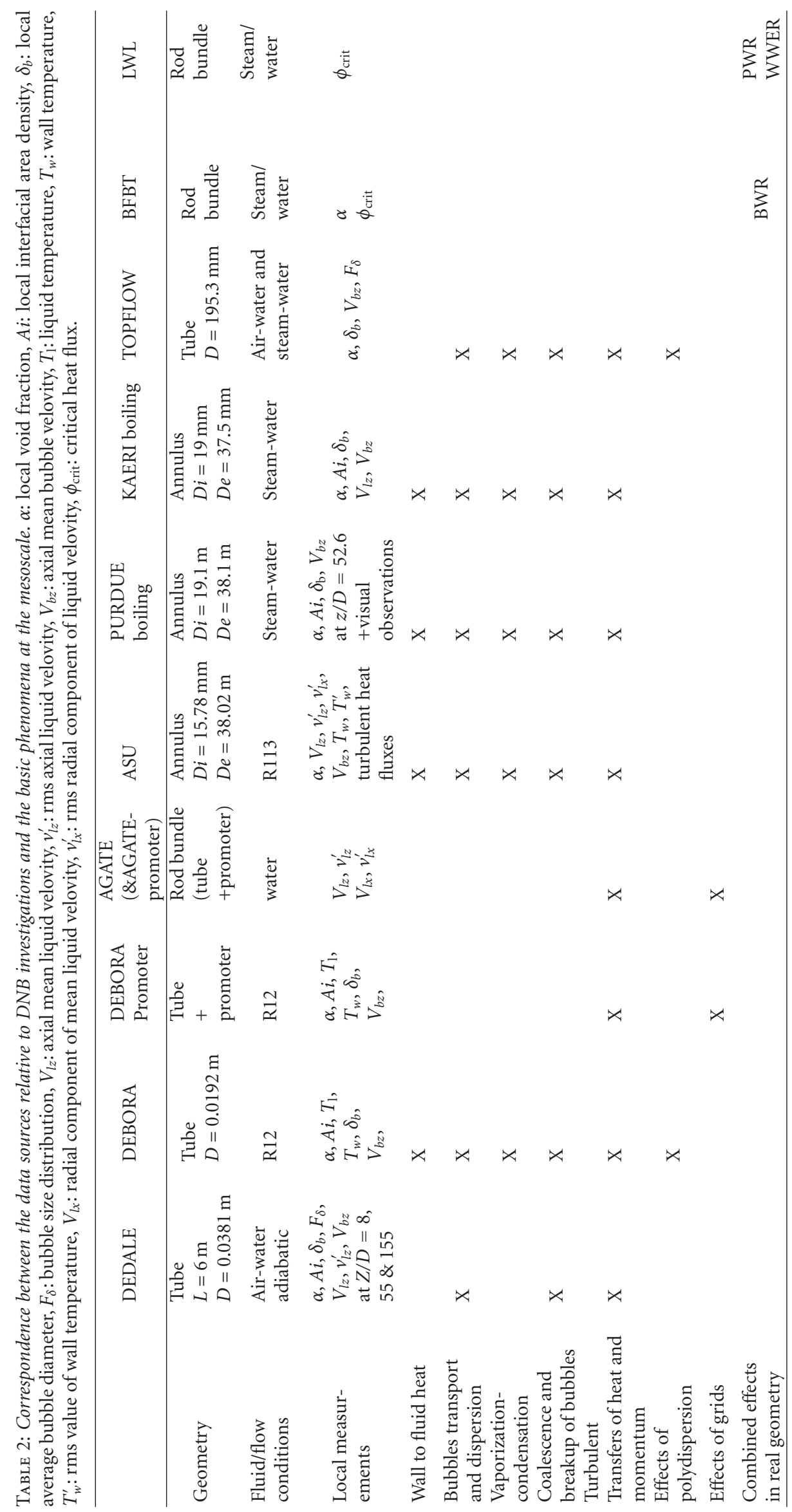


size spectrum. Another approach of the poly-dispersion is to use a multigroup model (MUSIG method) with mass (and momentum) equations written for several bubble sizes. These two methods are being used, evaluated, and compared on both DEBORA and TOPFLOW tests. The MUSIG method with several mass equations for different bubble sizes and at least two momentum equations has shown good capabilities for capturing all qualitative effects in TOPFLOW vertical pipe tests. The MMS has been applied to a subcooled boiling DEBORA test, demonstrating a significant effect of polydispersion on the condensation predictions. MUSIG and MMS still have to be further evaluated.

(4) Momentum transfer control the void distribution and it is necessary to model all the forces acting on the bubbles. The virtual mass force is not expected to play a very important role, and rather reliable models exist for the drag force. More effort should be paid to the modeling and validation of both lift and turbulent dispersion forces since available models are still often tuned. In particular, since the lift force may depend on the bubble size, it is now necessary to model poly-dispersion to take this into account.

(5) Turbulent transfers: liquid turbulence plays a very important role in boiling flows. It influences liquid temperature diffusion, bubble dispersion, bubble detachment, bubble coalescence, and breakup which affect the interfacial area. Then, the liquid turbulent scales have to be predicted correctly to model all these processes and this will require additional transport equations. The $k$-epsilon or SST method was used with some success in DEBORA and TOPFLOW. A bubble column was simulated with some success using the NURESIM platform with a SGS model by Niceno et al. [41]. However, LES was not found well adapted to DEDALE test simulations or boiling flow simulations.

(6) Wall-to-fluid transfers: modeling of velocity profiles in the near-wall boiling region was improved by implementing the two-phase wall function in momentum equations. Models were validated on ASU boiling flow tests [42]. More specific wall functions need to be developed for boiling flow for energy equations. Such wall functions should be able to provide converged solution with a reasonably coarse nodalization close to a heating wall. Present versions of CFD tools provide models for heat flux partitioning into convection to liquid, vaporization, and quenching. Such models are using several correlations for density of nucleation sites, bubble departure diameter, and frequency of bubble departure, which are not separately validated by the present data basis. The comparison of void fraction close to the wall with measurements in DEBORA and ASU tests gives an indication that the amount of vaporization is reasonably predicted and the comparison of Sauter mean bubble diameter close to the wall in DEBORA tests gives an indication that the bubble departure diameter is also reasonably predicted, but more detailed experimental data in prototypical convective boiling conditions would be necessary for a more rigorous validation. The absence of a physically based DNB criterion is also a difficulty, and one may argue that microscale effects may affect the CHF even more than the mesoscale effects which are modeled. In the far future, such microscale phenomena might be clarified by microvisualisation techniques of by DNS prediction. In medium term, an empirical DNB criterion may be envisaged which will require final validation on very representative conditions. Today a simple criterion based on a limit void fraction at the wall is implemented in Neptune-CFD which allows a switch from nucleate boiling to film boiling heat transfer model but it is not satisfactory and did not predict LWL CHF tests very well.

(7) First demonstration test cases were performed with Neptune-CFD calculations of critical heat flux tests in the LWL loop which is prototypical of WWER type core assemblies. Computational grid consists of 150000 hexahedral cells. Although the simulation is not fully successful quantitatively, Neptune showed the capability to model boiling flow in a complex industrial geometry and in reactor flow conditions up to CHF. CHF occurrence was predicted at the right location but with errors from $1 \%$ to $25 \%$ on the heat flux, which shows how far we still are from the final goal of the "local predictive approach."

\section{The DryOut}

4.1. The DryOut Phenomenology. Annular flow pattern usually is the predominant flow regime in upper core regions in boiling water reactors. The limitation of the total power obtained from each assembly is the occurrence of dryout. Increasing the heat flux above some critical value can lead to dryout that is associated with a sudden increase in the wall temperature, which, in turn, can destroy the cladding material and allow the radiation releases into the primary system. The phenomenology of dryout in annular mist flow was described in [43].

The liquid phase exists as a liquid film, which is attached to walls, and as droplets, which are carried in the central part of the channel by the vapour phase.

The mass flow rate in the liquid film is changing due to several mass transfer mechanisms.

(i) Due to hydrodynamic forces acting on the liquid film surface, certain amount of liquid from liquid film is entrained into the vapour core.

(ii) Another mechanism that is causing liquid film depletion is associated with evaporation due to heating applied to walls.

(iii) These two mechanisms must be counterbalanced by drop deposition from the vapour core to the liquid film surface to avoid film dryout.

There are several possible mechanisms that have been postulated for dryout (Hewitt, 1982 [44]).

(i) The liquid film dries by progressive entrainment and evaporation, which are prevailing in comparison to deposition, and dryout occurs when the film has gone.

(ii) Formation of a dry patch within the liquid film, causing such wall temperature increase that cannot be rewetted. In some situations a sudden disruption 
of liquid film may occur beyond which the wall surface is dry. The disruption mechanism is not fully understood yet, however, hydrodynamic mechanisms for the disruption are postulated.

(a) For very thin liquid films. dryout occurs when the rate of evaporation at the surface exceeds the rate at which droplets arrive at the surface due to deposition.

(b) For thicker liquid films, it is postulated that dryout may occur due to vapour film formation under the liquid film. The mechanism of forming this vapour film might be of the same type as described for the DNB mechanisms.

Annular regime in boiling flow is characterized by a thin liquid film flowing on the channel walls and a gas core flowing in the central part of the channel. The droplets in the gas core represent a larger interfacial area than the liquid film and thus can dominate heat and mass transport between the phases. System pressure drop is increased by droplet acceleration in the gas core, and depositing droplets contribute to corrosion by increasing local wall friction.

To some extent, the dryout is a more simple process than the DNB since one cannot list so many microscale phenomena which may play a role. In particular, if one first focuses on the first dryout scenario with entrainment and evaporation prevailing in comparison to deposition, only mesoscale phenomena have to be considered.

The most important mesoscale phenomena and parameters in annular flow affecting the occurrence of dryout are

(1) drop size,

(2) deposition of droplets,

(3) entrainment of droplets, and

(4) film thickness.

Drop Size in Disperse Two-Phase Flow. Drop size is an important parameter which affects the deposition rates and thus the dryout phenomenon. It can be described by a size PDF, $f d(d)$ defined as the probability that a droplet from the distribution will have a diameter of $d$. It is often required that drop size distribution is represented by a single weighted mean size.

Deposition Rate. Liquid droplets carried by a turbulent gas stream will deposit on bounding walls. Clearly, deposition rate will have an important influence on the dryout occurrence.

It may depend on several unresolved issues, such as turbulence-particle interactions and drop breakup and coalescence.

Deposition rate will depend on drop dispersion in turbulent flow where particle motion is primarily governed by interactions with eddies of various scales. Depending on the ratio of the particle response time to the eddy characteristic time, the dispersion can have different characters. If this ratio is very small, particles are following the continuous flow structure. When the ratio is close to 1 (the time constants of eddies and particles are of the same range of magnitude), the dispersion of drops can be even bigger than that observed in the carrier fluid. Finally, for high values of the ratio particles remain largely unaffected by eddies.

Typically, drop deposition is associated with two mechanisms: the diffusion process and the free-flight to the wall. For proper prediction of the deposition rate of droplets, both these mechanisms have to be taken into account. In addition, impinging conditions of a drop on a liquid surface have to be considered. When a single droplet impinges a liquid film, various phenomena can occur. The droplet can bounce from the surface or merge with the liquid film. Splash can occur when the drop kinetic energy is high enough. For conditions typical for BWRs, the liquid film is thin and the velocity of droplets is high, thus splashing and mergence are the key phenomena involved.

Entrainment Rate. Several mechanisms of drop entrainment from the liquid film have been identified. The dynamic impact of gas core causes generation of waves on the film surface, with droplets being separated and entrained from the crests of these waves. The creation and breakup of the disturbance waves play important roles in the drop entrainment process. Another entrainment mechanism is associated with splashing associated with drop deposition, as already mentioned in the previous section. Finally, in a heated channel with nucleate boiling in the film, entrainment can occur due to the action of vapour bubbles which induce splashing.

Liquid Film Thickness. Calculation of the liquid film thickness is necessary to predict the occurrence of dryout. To obtain the liquid film thickness and velocity, it is necessary to solve the mass and momentum conservation equations of the film in order to determine the film flowrate and pressure drop. This requires proper modeling of deposition, entrainment, and evaporation in mass equation and of the wall friction and interfacial friction in the momentum equation which depend on the wave structure of the film interface.

4.2. DryOut Data Basis. Early experiments were focused on the measurements of the total power, which was necessary for the dryout occurrence in a heated channel. A vast number of these experiments were performed for different conduit geometries in different flow conditions. The measurements for steam-water were done in round ducts, annuli, and rod clusters. Measurements in annuli covered the pressures of 30, 50, and 70 bar (Becker and Letzer [45]; Persson [46]). For a validation of models based on the analysis of wall film flows, experimental data of pressure drops, including wall shear stress and interfacial shear stress, which characterize liquid film thickness and the onset of entrainment, respectively, are required. Also, actual measurements of film flows, film thickness, wave amplitude, frequencies, and wave velocities are needed for the validation. Moreover, because complete physical models for droplet entrainment and droplet deposition are still not available, experimental data of these are 
needed to develop reliable correlations and/or computational models.

Würtz [47] has reported more than 2700 pressure drop measurements for steam-water and reviewed film flow measurements in steam-water mixtures in annular flow (see also Cousins \& Hewitt [48]). The film flows were measured both in tubes and in annuli and recently, Adamson and Anglart [49] provided high-pressure steam-water data.

An extensive review of existing measurements of deposition rate has been presented by Okawa et al. [50]. The deposition rates were predominantly measured in air-water systems with low pressures (see also Govan et al. [51]). The techniques employed are the double film extraction, thermal method, and tracer method

It was experimentally proven that the mode of the deposition is dependent on the droplet size. Observations of droplet motion (Andreussi [52]) show that larger droplets travel across the gas core at about their initial velocity in a constant direction until they are deposited. This mechanism of deposition has been called direct impaction. At higher gas velocities where the droplets are comparatively smaller, the effect of the initial momentum on droplet motion becomes negligible. In this case, the eddy diffusion mechanism of deposition prevails. Bates and Sheriff [53] have presented a summary of the previous work done on droplet size/velocity in vertical annular air-water two-phase flow. The drop size distribution was investigated by Fore et al. [54] and Fore and Dukler [55]. When a gas phase is flowing over a liquid film, several different flow regimes are possible depending on the magnitude of the gas velocity. For a very small gas velocity, the interface is relatively stable, however, as the gas velocity increases the interfacial waves appear. The amplitude and irregularity of waves become pronounced as the gas velocity is further increased. At sufficiently high gas flow, the capillary waves transform into large-amplitude roll waves (disturbance waves). Near the transition to the roll wave or at a still higher gas velocity, the onset of entrainment occurs.

One way to measure entrainment is to reach a quasiequilibrium state in the system where it is considered that deposition rate is equal to the entrainment rate. Okawa et al. [50] presented a summary of existing experiments for the equilibrium entrainment rate.

Table 3 summarizes the available data base for annularmist flow which can be used to validate CFD tools for dryout investigations.

4.3. State of The Art in DryOut Modeling Within The NURESIM Project. The following state of the art on the modeling of dryout by two-phase CFD results from the ongoing work in NURESIM.

(1) Basic model approach: in annular flows, the gas is a continuous phase and the liquid phase is split into a film which is continuous field and droplets as a dispersed field. The three-field model is naturally used in this flow conditions to benefit from the possibility to model separately the two liquid fields which have very different behaviours since the droplets have a high interfacial area and no wall friction whereas the film has a low interfacial area and has a friction along the wall. A simplified three-field model can be easily implemented in a two-fluid code by adding the film balance equations only in meshes along walls. The films are then treated as in a 1D model with mass momentum and energy equations written with a unique velocity component along vertical direction and a film thickness function of the vertical position only.

(2) Filtering or averaging procedure: considering flow in a BWR core in conditions close to nominal, a high velocity steady flow regime takes place with times scales associated to the passage of droplets being very small $(10-4,10-3$ seconds) and with droplet diameter being rather small (105 to $10-3 \mathrm{~m}$ ) compared to the hydraulic diameter (about $10-2 \mathrm{~m}$ ). These are perfect conditions to use a time average or ensemble average of equations as usually done in the RANS approach. All turbulent fluctuations and two-phase intermittency scales can be filtered since they are significantly smaller than scales of the mean flow. There may be a difficulty if film waves have to be simulated since it is not clear how the averaging of the RANS approach may filter or damp the disturbance waves.

(3) Identification of local interface structure: is necessary to select the adequate interfacial transfer laws and to determine the interfacial area. Here, there are two interfacial structures corresponding either to a dispersed liquid phase in a continuous gas in the core flow or a film surface with waves and with droplet entrainment of deposition along walls. A simple way to identify the two situations is to consider that the latter only takes place in meshes along the walls while the former takes place everywhere else. The characterisation of the droplet field may require the use of additional transport equations for the droplet number density, or the interfacial area of any statistical moment of the droplet size distribution function. Another approach of the poly-dispersion is to use a multigroup model with mass (and momentum) equations written for several droplet sizes. A more simple characterisation of the droplet field by using an algebraic expression of an average drop diameter will be used and evaluated during the project.

(4) Interfacial transfers: mass transfers affect the film thickness and it is necessary to model at least the droplet deposition, the entrainment and the vaporisation. A new droplet deposition model was proposed and models for entrainment and vaporization were proposed to be evaluated. Momentum transfers affect the film thickness, and it is necessary to model gravity, wall friction, and interfacial friction. Models for these forces were proposed to be evaluated. Energy transfers also affect the film thickness, and it is necessary to model the wall heat flux, the interfacial transfer, the evaporation, and the energy transfer due to deposition and entrainment. Models for these transfers are proposed to be evaluated. Interfacial heat and mass transfer also affect the droplet field, and models are necessary for the convective heat flux from steam to droplet interface and the radiation heat flux from walls to the droplets. The mechanical behaviour of the droplets is mainly controlled by gravity and interfacial friction. Again the drop size and poly-dispersion 
TABle 3: Data sources relative to dryout investigations. $Q_{\text {film }}$ : film flowrate, $\delta_{f}:$ film thickness, $\Delta P$ : pressure drop, $f_{w}:$ wave frequency, $C_{w}:$ wave velocity, $E$ : fraction of entrained liquid, $E_{\mathrm{eq}}$ : equilibrium entrainment rate, $Q_{\mathrm{dep}}$ : deposition rates.

\begin{tabular}{|c|c|c|c|c|}
\hline Reference & Measured value & Geometry & Fluid/heating & Flow conditions \\
\hline $\begin{array}{l}\text { Würtz, } 1978 \\
\text { [47] }\end{array}$ & $\begin{array}{l}\Delta P \\
Q_{\text {film }} \\
\delta_{f} \\
f_{w} \\
C_{w}:\end{array}$ & $\begin{array}{l}\text { Tube test section: } \\
D i=10 \mathrm{~mm}, L h=9.0 \mathrm{~m} \\
\text { Annulus section: } \\
D i=17 \mathrm{~mm} D e=26 \mathrm{~mm}, \\
L h=8.0 \mathrm{~m} ; 3.5 \mathrm{~m}\end{array}$ & $\begin{array}{l}\text { Steam-water adiabatic } \\
\text { and diabatic }\end{array}$ & $\begin{array}{l}P: 30,50,70, \text { and } 90 \text { bar } \\
G: 500-3000 \mathrm{~kg} / \mathrm{m}^{2} \mathrm{~s}\end{array}$ \\
\hline $\begin{array}{l}\text { Andreussi, } 1983 \\
{[52]}\end{array}$ & $\Delta P$ & $\begin{array}{l}\text { Plexiglass tube } \\
D i=24 \mathrm{~mm} \\
L=5 \mathrm{~m}\end{array}$ & Air-water adiabatic & $\begin{array}{l}P: \text { atmospheric } \\
G l: 9.73-200.3 \mathrm{~g} / \mathrm{s} \\
G g: 17.5-50.3 \mathrm{~g} / \mathrm{s}\end{array}$ \\
\hline $\begin{array}{l}\text { Govan et al., } \\
1989[51]\end{array}$ & $\begin{array}{l}\Delta P \\
\tau w \\
\tau I \\
Q_{\mathrm{dep}}\end{array}$ & $\begin{array}{l}\text { LOTUS test rig } \\
\text { tubular section } \\
D i=31.8 \mathrm{~mm} \\
L=23 \mathrm{~m}\end{array}$ & Air-water adiabatic & $\begin{array}{l}P: 2.4 \text { bar } \\
G l: 100,200,300,500 \mathrm{~kg} / \mathrm{m}^{2} \mathrm{~s} \\
G g: 70-240 \mathrm{~kg} / \mathrm{m}^{2} \mathrm{~s} \\
\text { Temperature ambient }\end{array}$ \\
\hline $\begin{array}{l}\text { Cousins and } \\
\text { Hewitt, } 1968 \\
{[48]}\end{array}$ & $\begin{array}{l}Q_{\text {film }} \\
C_{w} \\
E\end{array}$ & $\begin{array}{l}\text { acrylic resin tube } \\
\text { Di: } 9.525 \mathrm{~mm}\end{array}$ & Air-water adiabatic & $\begin{array}{l}P: 2 \text { bar } \\
G g: 18.14 \& 31.75 \mathrm{~kg} / \mathrm{h} \\
\text { Temperature ambient }\end{array}$ \\
\hline $\begin{array}{l}\text { Adamsson and } \\
\text { Anglart, } 2005 \\
{[49]}\end{array}$ & $Q_{\text {film }}$ & $\begin{array}{l}\text { Tube test section } \\
D i: 13.9 \mathrm{~mm} \\
L h: 3.65 \mathrm{~m} \\
\text { various power profiles }\end{array}$ & Steam-water diabatic & $\begin{array}{l}P: 70 \text { bar } \\
G: 500-1750 \mathrm{~kg} / \mathrm{m}^{2} \mathrm{~s}\end{array}$ \\
\hline $\begin{array}{l}\text { Okawa et al., } \\
2005[50]\end{array}$ & $\begin{array}{l}\text { Deposition mass } \\
\text { transfer } \\
\text { coefficients } \\
\text { Droplet } \\
\text { concentration } \\
E_{\mathrm{eq}}\end{array}$ & $\begin{array}{l}\text { Stainless steel tube } \\
\text { Di: } 5 \mathrm{~mm} \\
L: 3670 \mathrm{~mm}\end{array}$ & Air-water & $\begin{array}{l}P: 1.4-7.6 \text { bar } \\
\text { Temperature ambient } \\
G l: 201-1264 \mathrm{~kg} / \mathrm{m}^{2} \mathrm{~s} \\
G g: 173-627 \mathrm{~kg} / \mathrm{m}^{2} \mathrm{~s}\end{array}$ \\
\hline $\begin{array}{l}\text { Fore et al., } 2002 \\
{[54]}\end{array}$ & $\begin{array}{l}\text { Drop size } \\
\text { distribution }\end{array}$ & $\begin{array}{l}\text { Stainless steel duct } \\
D i: 9.67 \mathrm{~mm} \\
L: 3.4 \mathrm{~m}\end{array}$ & Nitrogen-water & $\begin{array}{l}\text { Pressure } 3.4 \text { and } 17 \mathrm{bar} \\
\text { Temperature } 38^{\circ} \mathrm{C} \\
\text { Ql: } 0.0157 \text { and } 0.126 \mathrm{~kg} / \mathrm{s} \\
\mathrm{Jg}: 5,7,17 \text { and } 23 \mathrm{~m} / \mathrm{s}\end{array}$ \\
\hline $\begin{array}{l}\text { Fore and } \\
\text { Dukler, } 1995 \\
{[55]}\end{array}$ & $\begin{array}{l}\text { Drop size } \\
\text { distribution }\end{array}$ & $\begin{array}{l}\text { Vertical tube } \\
\text { Di: } 50.8 \mathrm{~mm} \\
L: 7.6 \mathrm{~m}\end{array}$ & $\begin{array}{l}\text { Air-water } \\
\text { air-water+glycerine } \\
(50 \% \mathrm{mix})(6 \mathrm{cP} \\
\text { liquid })\end{array}$ & \\
\hline $\begin{array}{l}\text { Andreussi, } 1983 \\
{[52]}\end{array}$ & $\begin{array}{l}E, \\
\text { Rate of liquid } \\
\text { interchange }\end{array}$ & $\begin{array}{l}\text { Plexiglass tube } \\
\text { Di: } 24 \mathrm{~mm} \\
L: 5 \mathrm{~m}\end{array}$ & Air-water adiabatic & $\begin{array}{l}\text { Pressure: atmospheric } \\
Q l: 9.73-200.3 \mathrm{~g} / \mathrm{s} \\
G g: 17.5-50.3 \mathrm{~g} / \mathrm{s}\end{array}$ \\
\hline
\end{tabular}

effects play an important role on these transfers. Models have still to be developed for these transfers on the droplet-vapour interface.

(5) Turbulent transfers: liquid turbulence plays a very important role in annular flows in a BWR core. It influences droplet deposition, droplet coalescence, and breakup which affects the drop size and consequently the deposition. Then, the vapour turbulent scales have to be predicted correctly to model all these processes and this will require additional transport equations to the three-field model. The $k$-epsilon method was used in a Eulerian-Lagrangian approach to investigate the deposition

\section{Conclusion}

While current industrial methods for CHF still use the subchannel analysis and empirical CHF correlations, the use of CFD already proved its potential interest in fine-scale investigations of boiling flows for a better understanding of sensitive flow processes. The "local predictive approach" where CHF empirical correlations would be based on local $\mathrm{T} / \mathrm{H}$ parameters provided by CFD is not yet available but, with the present state of the modeling, CFD can already be used to subsequently help new fuel assembly design and to develop better CHF predictions in both PWR and BWR. 


\section{Acknowledgment}

The NURESIM project is partly funded by the European Commission within the Sixth Framework Programme.

\section{References}

[1] D. Bestion, H. Paillère, A. Latrobe, et al., "EUROpean project for future advances in sciences and technology for nuclear engineering thermalhydraulics (EUROFASTNET)," in Proceedings of the EU Research in Reactor Safety, Conclusion Symposium on Shared Cost and Concerted Actions (FISA '03), EC Luxembourg, November 2003.

[2] H. Paillère, A. Kumbaro, J. Garcia-Cascales, et al., "Advanced 3D two-phase flow simulation tool for application to reactor safety (ASTAR)," in Proceedings of the EU Research in Reactor Safety, Conclusion Symposium on Shared Cost and Concerted Actions (FISA '03), EC Luxembourg, November 2003.

[3] M. Scheuerer, F. Menter, I. Tóth, et al., "Evaluation of computational fluid dynamic methods for reactor safety analyses (ECORA)," in Proceedings of the EU Research in Reactor Safety, Conclusion Symposium on Shared Cost and Concerted Actions (FISA '03), EC Luxembourg, November 2003.

[4] A. Guelfi, M. Boucker, J. M. Hérard, et al., "A new multiscale platform for advanced nuclear thermalhydraulics status and prospects of the NEPTUNE project," in Proceedings of the 11th International Topical Meeting on Nuclear Reactor Thermalhydraulics (NURETH-11), Avignon, France, October 2005.

[5] D. Bestion and A. Guelfi, "Status and perspective of twophase flow modelling in the NEPTUNE multi-scale thermalhydraulic platform for nuclear reactor simulation," Nuclear Engineering and Technology, vol. 37, no. 6, pp. 511-524, 2005.

[6] D. Bestion and A. Guelfi, "Multiscale analysis of nuclear reactors thermalhydraulics - the NEPTUNE project," La Houille Blanche, no. 5, pp. 65-74, 2005.

[7] D. Bestion, H. Anglart, B. L. Smith, et al., "Extension of CFD codes to two-phase flow safety problems," Technical Note NEA/SEN/SIN/AMA(2006)2, OECD Nuclear Energy Agency, Paris, France, 2006.

[8] C. Grossetête, Caractérisation expérimentale et simulations de l'évolution d'un écoulement diphasique à bulles ascendant dans une conduite verticale, Ph.D. thesis, Ecole Centrale Paris, Paris, France, 1995.

[9] C. Morel, Modélisation multidimensionnelle des écoulements diphasiques gaz-liquide-application à la simulation des écoulements à bulles en conduite verticale, Ph.D. thesis, Ecole Centrale Paris, Paris, France, 1997.

[10] W. Yao and C. Morel, "Volumetric interfacial area prediction in upward bubbly two-phase flow," International Journal of Heat and Mass Transfer, vol. 47, no. 2, pp. 307-328, 2004.

[11] J. Garnier, E. Manon, and G. Cubizolles, "Local measurements on flow boiling of refrigerant 12 in a vertical tube," Multiphase Science and Technology, vol. 13, no. 1-2, pp. 1-111, 2001.

[12] C. Morel, Y. Wei, and D. Bestion, "Three dimensional modelling of boiling flow for the NEPTUNE code," in Proceedings of the 10th International Topical Meeting on Nuclear Reactor Thermalhydraulics (NURETH-10), Seoul, Korea, October 2003.

[13] M. Boucker, A. Guelfi, S. Mimouni, P. Péturaud, D. Bestion, and E. Hervieu, "Towards the prediction of local thermalhydraulics in real PWR core conditions using NEPTUNE_CFD software," in Proceedings of the Workshop on Modelling and Measurements of Two-Phase Flows and Heat Transfer in Nuclear Fuel Assemblies, KTH, Stockholm, Sweden, October 2006.

[14] G. Serre and D. Bestion, "Progress in improving two-fluid model in system code using turbulence and interfacial area equations," in Proceedings of the 11th International Topical Meeting on Nuclear Reactor Thermalhydraulics (NURETH-11), Avignon, France, October 2005.

[15] R. P. Roy, V. Velidandla, S. P. Kalra, and P. Peturaud, "Local measurements in the two-phase region of turbulent subcooled boiling flow," Journal of Heat Transfer, vol. 116, no. 3, pp. 660669, 1994.

[16] S. Kang and R. P. Roy, "Vapor phase measurements in subcooled boiling flow," Journal of Heat Transfer, vol. 124, no. 6, pp. 1207-1209, 2002.

[17] C. Morel, S. Mimouni, M. Lavieville, and M. Boucker, "R113 boling bubbly flow in an annular geometry simulated with the NEPTUNE code," in Proceedings of the 11th International Topical Meeting on Nuclear Reactor Thermalhydraulics (NURETH11), Avignon, France, October 2005.

[18] R. P. Roy, V. Velidandla, and S. P. Kalra, "Velocity field in turbulent subcooled boiling flow," Journal of Heat Transfer, vol. 119, no. 4, pp. 754-766, 1997.

[19] M. D. Bartel, Experimental investigation of subcooled boiling, M.S.N.E. thesis, Purdue University, West Lafayette, Ind, USA, 1999.

[20] M. D. Bartel, M. Ishii, Y. Mi, T. Masukawa, R. Situ, and M. Mori, "Experimental investigation of subcooled boiling under BWR flow conditions," in Proceedings of the 9th International Topical Meeting on Nuclear Reactor Thermalhydraulics (NURETH-9), San Francisco, Calif, USA, October 1999.

[21] M. D. Bartel, M. Ishii, T. Masukawa, Y. Mi, and R. Situ, "Interfacial area measurements in subcooled flow boiling," Nuclear Engineering and Design, vol. 210, no. 1-3, pp. 135-155, 2001.

[22] R. Situ, T. Hibiki, X. Sun, Y. Mi, and M. Ishii, "Flow structure of subcooled boiling flow in an internally heated annulus," International Journal of Heat and Mass Transfer, vol. 47, no. 24, pp. 5351-5364, 2004.

[23] R. Situ, Y. Mi, M. Ishii, and M. Mori, "Photographic study of bubble behaviors in forced convection subcooled boiling," International Journal of Heat and Mass Transfer, vol. 47, no. 17-18, pp. 3659-3667, 2004.

[24] R. Situ, T. Hibiki, M. Ishii, and M. Mori, "Bubble lift-off size in forced convective subcooled boiling flow," International Journal of Heat and Mass Transfer, vol. 48, no. 25-26, pp. 55365548, 2005.

[25] B. Končar, I. Kljenak, and B. Mavko, "Modelling of local twophase flow parameters in upward subcooled flow boiling at low pressure," International Journal of Heat and Mass Transfer, vol. 47, no. 6-7, pp. 1499-1513, 2004.

[26] B. Končar, I. Kljenak, and B. Mavko, "Nucleate boiling flow simulation with coupling of Eulerian and Lagrangian methods," in Proceedings of the ASME Summer Heat Transfer Conference (HT '05), vol. 2, pp. 69-77, San Francisco, Calif, USA, July 2005.

[27] T. H. Lee, G. C. Park, and D. J. Lee, "Local flow characteristics of subcooled boiling flow of water in a vertical concentric annulus," International Journal of Multiphase Flow, vol. 28, no. 8, pp. 1351-1368, 2002.

[28] G. H. Yeoh and J. Y. Tu, "A bubble mechanistic model for subcooled boiling flow predictions," Numerical Heat Transfer, Part B, vol. 45, no. 5, part B, pp. 475-493, 2004. 
[29] G. H. Yeoh and J. Y. Tu, "Thermal-hydrodynamic modeling of bubbly flows with heat and mass transfer," AIChE Journal, vol. 51, no. 1, pp. 8-27, 2005.

[30] J. Y. Tu, G. H. Yeoh, G.-C. Park, and M.-O. Kim, "On population balance approach for subcooled boiling flow prediction," Journal of Heat Transfer, vol. 127, no. 3, pp. 253 264, 2005.

[31] G. H. Yeoh and J. Y. Tu, "A unified model considering force balances for departing vapour bubbles and population balance in subcooled boiling flow," Nuclear Engineering and Design, vol. 235, no. 10-12, pp. 1251-1265, 2005.

[32] A. Schaffrath, A.-K. Krüssenberg, F.-P. Weiss, et al., "TOPFLOW-a new multipurpose thermalhydraulic test facility for the investigation of steady state and transient two phase flow phenomena," Kerntechnik, vol. 66, no. 4, pp. 209-213, 2001.

[33] H.-M. Prasser, A. Böttger, and J. Zschau, "A new electrodemesh tomograph for gas-liquid flows," Flow Measurement and Instrumentation, vol. 9, no. 2, pp. 111-119, 1998.

[34] H.-M. Prasser, E. Krepper, and D. Lucas, "Evolution of the two-phase flow in a vertical tube-decomposition of gas fraction profiles according to bubble size classes using wiremesh sensors," International Journal of Thermal Sciences, vol. 41, no. 1, pp. 17-28, 2002.

[35] H.-M. Prasser, J. Zschau, D. Peters, G. Pietzsch, W. Taubert, and M. Trepte, "Fast wire-mesh sensors for gas-liquid flowsvisualization with up to 10000 frames per second," in Proceedings of the International Congress on Advanced Nuclear Power Plants (ICAPP '02), Hollywood, Fla, USA, June 2002, paper \# 1055.

[36] H.-M. Prasser, D. Scholz, and C. Zippe, "Bubble size measurement using wire-mesh sensors," Flow Measurement and Instrumentation, vol. 12, no. 4, pp. 299-312, 2001.

[37] A. Tomiyama, "Struggle with computational bubble dynamics," in Proceedings of the 3rd International Conference on Multiphase Flow (ICMF'98), pp. 1-18, Lyon, France, June 1998.

[38] H.-M. Prasser, M. Beyer, A. Böttger, et al., "Influence of the pipe diameter on the structure of the gas-liquid interface in a vertical two-phase pipe flow," in Proceedings of the 10th International Topical Meeting on Nuclear Reactor Thermalhydraulics (NURETH-10), Seoul, Korea, October 2003.

[39] D. Lucas and H.-M. Prasser, "Steam bubble condensation in sub-cooled water in case of co-current vertical pipe flow," Nuclear Engineering and Design, vol. 237, no. 5, pp. 497-508, 2007.

[40] A. Inoue, T. Kurosu, T. Aoki, M. Yagi, T. Mitsutake, and S. Morooka, "Void fraction distribution in BWR fuel assembly and evaluation of subchannel code," Journal of Nuclear Science and Technology, vol. 32, no. 7, pp. 629-640, 1995.

[41] B. Niceno, B. Smith, and M. T. Dhotre, "Euler-Euler large eddy simulation of a square cross section bubble column using the NURESIM CFD platform," in Proceedings of the 12th International Topical Meeting on Nuclear Reactor Thermalhydraulics (NURETH-12), Pittsburgh, Pa, USA, SeptemberOctober 2007.

[42] B. Končar, "Use of two-phase wall function for simulation of boiling flow," in Proceedings of the 12th International Topical Meeting on Nuclear Reactor Thermalhydraulics (NURETH-12), Pittsburgh, Pa, USA, September-October 2007.

[43] D. Bestion, D. Caraghiaur, H. Anglart, et al., "Review of the existing data basis for the validation of models for CHF," NURESIM Deliverable D2.2.1, http://www.nuresim.com.
[44] G. F. Hewitt, "Burnout," in Handbook of Multiphase Systems, G. Hetsroni, Ed., pp. 66-141, Hemisphere, New York, NY, USA, 1982.

[45] K. M. Becker and A. Letzer, "An experimental study of the effect of the axial heat flux distribution on the dryout conditions in a $3650 \mathrm{~mm}$ long annulus," International Journal of Multiphase Flow, vol. 7, no. 1, pp. 47-61, 1981.

[46] P. Persson, "Measurements and analysis of dry out in annular geometry with two sided heating with uniform and nonuniform axial power and the influence of spacers and spacer positions," SKI/KSU/KTH Project, 2001.

[47] J. Würtz, "An experimental and theoretical investigation of annular steam-water flow in tubes and annuli at 30 to 90 bar," Risø Report 372, Risø National Laboratory, Roskilde, Denmark, 1978.

[48] L. B. Cousins and G. F. Hewitt, "Liquid phase mass transfer in annular two-phase flow: droplet deposition and liquid entrainment," UKAEA Report AERE-R 5657, Atomic Energy Research Establishment, Harwell, UK, 1968.

[49] C. Adamsson and H. Anglart, "Experimental investigation of the liquid film for annular flow in a tube with various axial power distributions," in Proceedings of the 11th International Topical Meeting on Nuclear Reactor Thermalhydraulics (NURETH-11), Avignon, France, October 2005.

[50] T. Okawa, A. Kotani, and I. Kataoka, "Experiments for liquid phase mass transfer rate in annular regime for a small vertical tube," International Journal of Heat and Mass Transfer, vol. 48, no. 3-4, pp. 585-598, 2005.

[51] A. H. Govan, G. F. Hewitt, D. G. Owen, and G. Burnett, "Wall shear stress measurements in vertical air-water annular twophase flow," International Journal of Multiphase Flow, vol. 15, no. 3, pp. 307-325, 1989.

[52] P. Andreussi, "Droplet transfer in two-phase annular flow," International Journal of Multiphase Flow, vol. 9, no. 6, pp. 697713, 1983.

[53] C. J. Bates and J. M. Sheriff, "High data rate measurements of droplet dynamics in a vertical gas-liquid annular flow," Flow Measurement and Instrumentation, vol. 3, no. 4, pp. 247-256, 1992.

[54] L. B. Fore, B. B. Ibrahim, and S. G. Beus, "Visual measurements of droplet size in gas-liquid annular flow," International Journal of Multiphase Flow, vol. 28, no. 12, pp. 1895-1910, 2002.

[55] L. B. Fore and A. E. Dukler, "The distribution of drop size and velocity in gas-liquid annular flow," International Journal of Multiphase Flow, vol. 21, no. 2, pp. 137-149, 1995. 

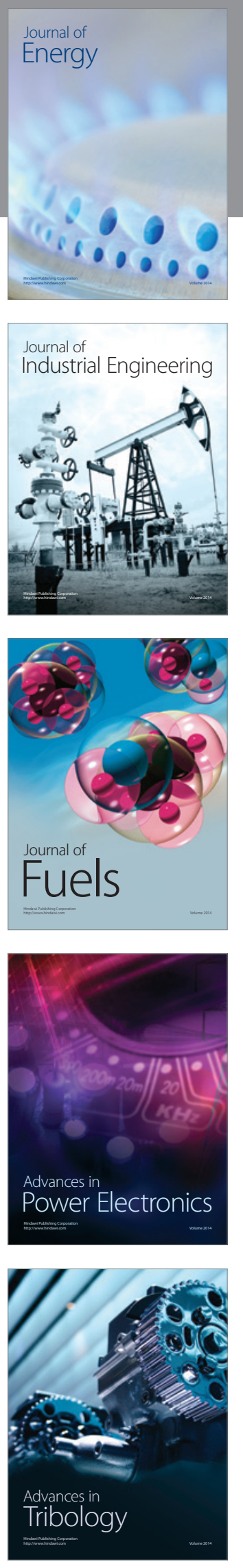
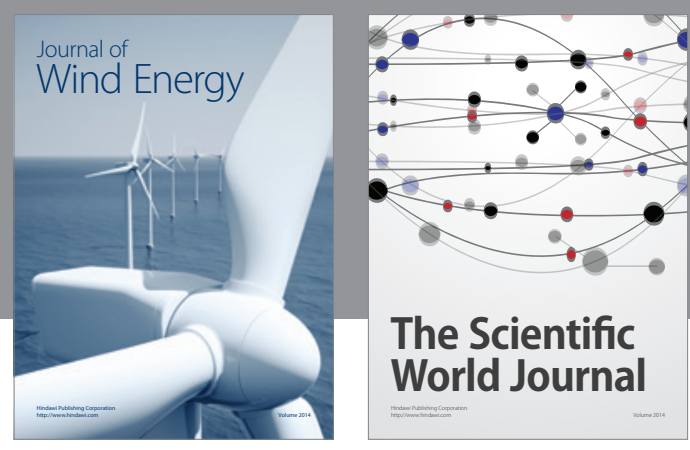

The Scientific World Journal

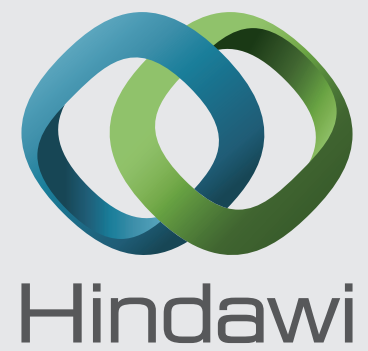

Submit your manuscripts at http://www.hindawi.com
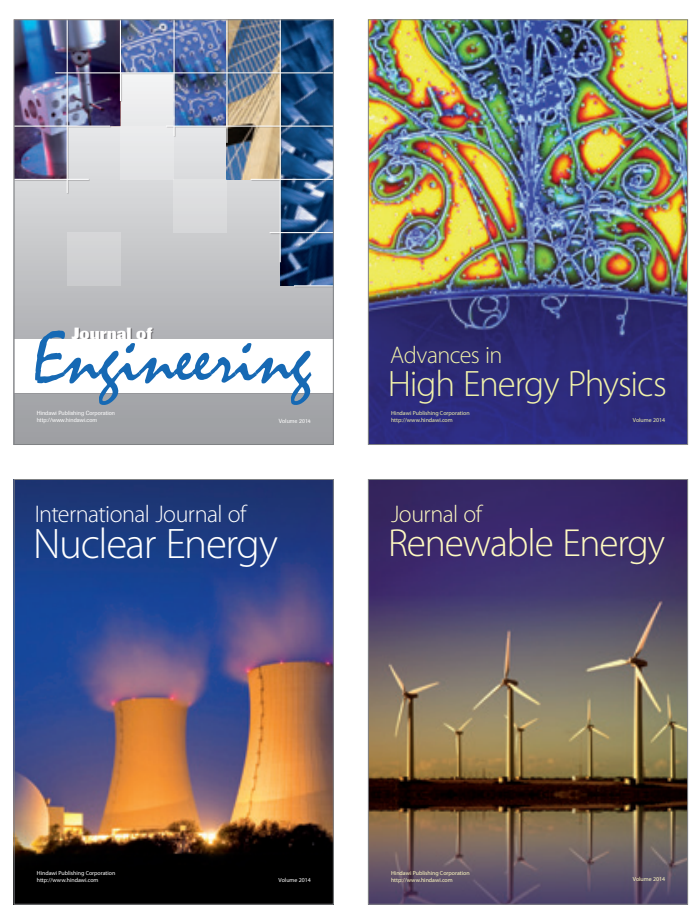

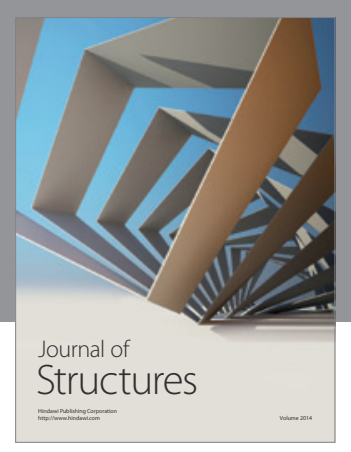

Rotating
Mechinery
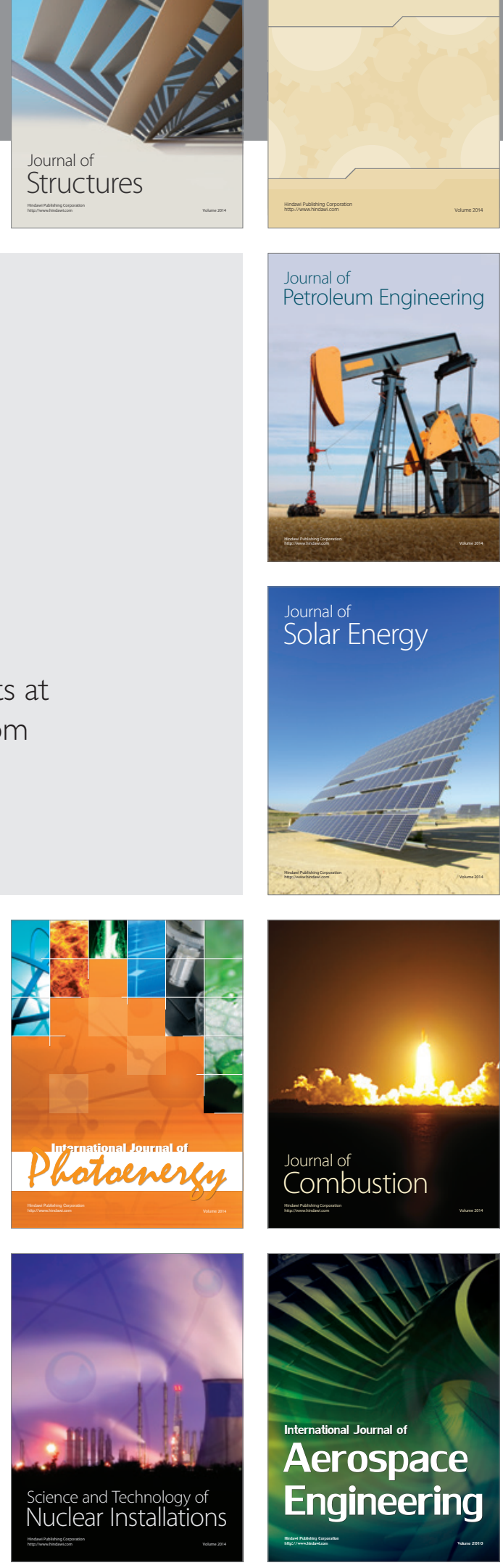